ORIGINAL ARTICLE

\title{
Clinicomycological Profile of Onychomycosis in Jaipur, Rajasthan, India
}

\author{
Richa Sharma
}

\begin{abstract}
Aims and objectives: Onychomycosis is a chronic fungal infection of nails. The clinical diagnosis of onychomycosis needs to be confirmed by direct microscopy and culture for identification of specific pathogen and proper selection of antifungal treatment. The study aimed to determine the prevalence of onychomycosis and cultural positivity of onychomycosis with respect to various etiological agents.

Introduction: Dermatophytes are the most common pathogens of onychomycosis, yeasts and nondermatophyte moulds can also be found as causative agents of onychomycosis.

Materials and methods: Nail clippings from 90 clinically suspected cases of onchomycosis were collected from OPD at Department of Dermatology, Venerology and Leprology, SMS and ESIC hospital, Jaipur. Detailed history of trauma, infection, occupation, diabetes, personal habits (smoking etc.) were taken Diagnosis was based on direct microscopy by $20 \% \mathrm{KOH}$ examination method and fungal culture on SDA and Dermatophyte Test Media.

Results: Out of 90 cases of onychomycosis patients, 80 (88.9\%) were found $\mathrm{KOH}$ positive and 33 (36.7\%) were positive in culture. In the present study, dermatophytes, nondermatophytes and yeasts were found etiological agents of onychomycosis. Distal subungual onchomycosis was found common type of onychomycosis in patients. Among the culture positive cases, Trichophyton rubrum was found the most prevalent species followed by T.mentagrophyte and T.tonsurans. Nondermatophyte molds were also isolated from white superficial onychomycosis and Candida species was isolated from Candida onychomycosis. Majority of patients were more prevalent in the age group of 41-50 and 51-60 years and males were commonly affected in our study. In the study, it was reported that, majority of patients that are infected with onychomycosis infection were service class and sportsmen followed by labours, housewives, unemployed, students and farmers.

Conclusion: Based on this study it could be concluded that, onychomycosis is an important public health problem and accurate diagnosis of onychomycosis by direct microscopy and fungal culture is an essential requirement for appropriate management of such cases.

Keywords: Dermatophytes, Onychomycosis, Nondermatophytes molds, Yeast

Journal of Mahatma Gandhi University of Medical Sciences and Technology (2018): 10.5005/.jp-journals-10057-0070
\end{abstract}

\section{INTRODUCTION}

Onychomycosis is life threatening, its high incidence and prevalence and the associated morbidity makes it an important public health problem. Onychomycosis in immunocompromised patients can pose a major serious health problem. Onychomycosis refers to the invasion of the nail plate by a fungus ${ }^{1}$. The infection may be due to a dermatophyte, yeast or non dermatophyte mould ${ }^{2,3}$. A number of factors contribute to the growing incidence of fungal nail infections includes increasing age, trauma to the nail, diabetes, immunosuppression, poor peripheral circulation and tinea pedis 4 . Many patients with fungal nail infections experience serious physical, psychological, social, and occupational ill-effects. Onychomycosis affects approximately $5 \%$ of the population worldwide and about $30 \%$ of cutaneous mycotic infections. Dermatophytes are the major cause of superficial infections, however, infections caused by non dermatophytes also may be common in India. Perhaps 50\% of all nail diseases are caused by fungi that invade the nail unit through the nail bed or nail plate. Often, more than one type of organism is involved. Dermatophytes are the most frequently implicated agents and out of these Trichophyton rubrum and Trichophyton interdigitale (formerly Trichophyton mentagrophytes var interdigitale) are responsible for nearly $90 \%$ of toenail and at least $50 \%$ fingernail onychomycosis. Several clinical types of onychomycosis have been recognized. Primary includes clinical variants like distal subungual onychomycosis (DSO), white superficial onychomycosis (WSO), proximal subungual onychomycosis (PSO), Candida onychomycosis and total dystrophic onychomycosis (TDO). Diagnosis is primarily based upon $\mathrm{KOH}$ examination, culture and histopathological

\section{Assistant Professor}

Department of Microbiology, Mahatma Gandhi University of Medical Science and Technology, Jaipur, Rajasthan, India

Corresponding Author: Richa Sharma, Assistant Professor, Department of Microbiology, Mahatma Gandhi University of Medical Science and Technology, Jaipur, Rajasthan, India, Phone: 9414315908, e-mail: richa.phd.15@gmail.com

How to cite this article: Sharma R. Clinicomycological Profile of Onychomycosis in Jaipur, Rajasthan, India. J Mahatma Gandhi Univ Med Sci Tech 2018;3(1):21-24.

Source of support: Nil

Conflict of interest: None

examination of nail clippings or nail biopsies. Men are affected more frequently possibly due to frequent nail damage from sports and leisure activities. ${ }^{5}$ Dermatophytes account for most (90\%) cases of onychomycosis of toenails and at least $50 \%$ cases of fingernail infection. ${ }^{6}$

\section{Materials and Methods}

Ninety clinically suspected cases of onchomycosis attending the Dermatology, OPD, SMS and ESIC hospital, Jaipur for the period of one year were included in this study. The most severely affected nail was thoroughly cleaned with $70 \%$ alcohol and nail clipping/ scrapping was collected. A part of this sample was dissolved in $20 \%$ potassium hydroxide $(\mathrm{KOH})$ and examined under the light microscope for fungal elements. Two sets of media (1) Sabouraud's 
Table 1: Culture and KOH positive results of onychomycosis

\begin{tabular}{llllll}
\hline Mycosis & Total no of cases & $\mathrm{KOH}+v e$ & \% of $\mathrm{KOH}+v e$ & Culture +ve & $\%$ Culture +ve \\
\hline Onychomycosis & 90 & 80 & $88.9 \%$ & 33 & $36.7 \%$ \\
\hline
\end{tabular}

dextrose agar (SDA) supplemented with cycloheximide $(100 \mu \mathrm{g} / \mathrm{ml})$ and chloramphenicol $(50 \mu \mathrm{g} / \mathrm{ml})$ (2) SDA without cycloheximide supplement were prepared for fungal culture. Both these culture tubes were incubated at $37^{\circ} \mathrm{C}$ and $28^{\circ} \mathrm{C}$ respectively for four to six weeks. Dermatophyte test medium was also used for primary isolation. The culture slopes showing fungal growth were examined for colony characters like texture of colony, surface of colony, colour of colony and pigment production. Detailed history of trauma, infection, occupation, diabetes, personal habits (smoking etc.) were taken.

\section{RESULTS}

Onychomycosis (Tinea unguium) was reported as common superficial fungal infection in human beings at Jaipur. Out of 90 cases of onychomycosis patients, 80 (88.9\%) were found $\mathrm{KOH}$ positive and
33 (36.7\%) were positive in culture (Table 1). Dermatophytes are the most frequently implicated causative agents in onychomycosis. In the present study, dermatophytes, nondermatophytes and yeasts were found etiological agents of onychomycosis. Distal subungual onchomycosis was found common type of onychomycosis in patients (Fig. 1). T.rubrum was found the most prevalent species isolated from 10 (33.3\%) cases out of 33 culture positive cases (Table 2). T.rubrum has been reported from distal subungual and proximal subungual onychomycosis. The second commonest dermatophytes isolated was T.mentagrophytes from 7 (21.2\%) paients. It was isolated from distal subungual and proximal subungual onychomycosis. The third commonest etiological agent isolated was T. tonsurans. It was isolated from 4 (12.1\%) patients, out of 33 culture positive cases. Aspergillus niger and Aspergillus fumigatus was the fourth etioogical agent isolated from 6 patients,
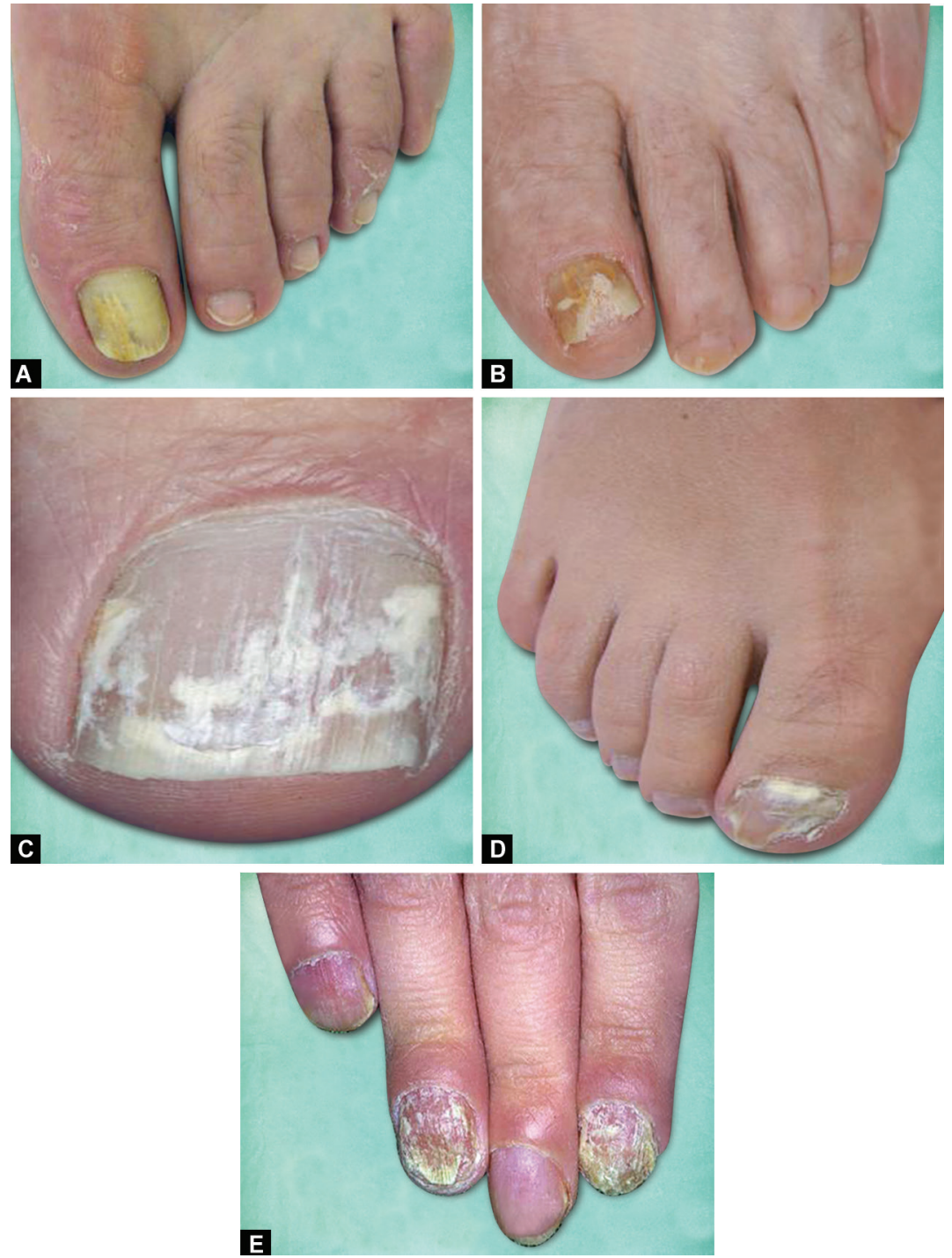

Figs $1 \mathrm{~A}$ to E: Photographs showing different clinical types of onychomycosis; (A and B) Distal subungual onychomycosis; (C) White superficial onychomycosis; (D) Proximal subungual onychomycosis; (E) Candida onychomycosis 
Table 2: Distribution of onychommycosis patients positive by culture according to age groups and sex

\begin{tabular}{|c|c|c|c|c|c|c|c|c|c|c|}
\hline \multirow{2}{*}{$\begin{array}{l}\text { Clinical type } \\
\text { Age group }\end{array}$} & \multicolumn{2}{|c|}{$\begin{array}{l}\text { Distal subungual } \\
\text { onychomycosis }\end{array}$} & \multicolumn{2}{|c|}{$\begin{array}{l}\text { Proximal } \\
\text { subungual } \\
\text { onychomycosis }\end{array}$} & \multicolumn{2}{|c|}{$\begin{array}{l}\text { White superficial } \\
\text { onychomycosis }\end{array}$} & \multicolumn{2}{|c|}{$\begin{array}{l}\text { Canndida } \\
\text { onychomycosis }\end{array}$} & \multicolumn{2}{|l|}{ Total } \\
\hline & Male\% & Female \% & Male\% & Female \% & Male\% & Female \% & Male\% & Female \% & Male\% & Female \% \\
\hline $0-10$ & - & - & - & - & - & - & - & - & - & - \\
\hline $16-30$ & - & - & - & - & - & - & - & - & - & - \\
\hline $31-40$ & $2(6.1)$ & - & $1(3.0)$ & - & - & - & - & - & $3(9.1)$ & - \\
\hline $41-50$ & $8(24.2)$ & $1(3.0)$ & $2(6.1)$ & - & $1(3.0)$ & - & - & - & $11(33.3)$ & $1(3.0)$ \\
\hline $51-60$ & $6(18.2)$ & $1(3.0)$ & - & $1(3.0)$ & $4(12)$ & $2(6.1)$ & $1(3.0)$ & $1(3.0)$ & $11(33.3)$ & $5(15.1)$ \\
\hline$>60$ & - & - & - & - & $2(6.1)$ & - & - & - & $2(6.1)$ & - \\
\hline Total & $16(48.5)$ & $2(6.1)$ & $3(9.1)$ & $1(3.0)$ & $7(21.2)$ & $2(6.1)$ & $1(3.0)$ & $1(3.0)$ & $27(81.8)$ & $6(18.2)$ \\
\hline
\end{tabular}

Table 3: Correlation between clinical types of onychomycosis and mycological findings

\begin{tabular}{|c|c|c|c|c|c|c|c|c|c|c|}
\hline Clinical Type & $\begin{array}{l}\text { T. rubrum } \\
\%\end{array}$ & $\begin{array}{l}\text { T. mentagro- } \\
\text { phyte } \%\end{array}$ & $\begin{array}{l}\text { T. tonsurans } \\
\%\end{array}$ & $\begin{array}{l}\text { A. niger } \\
\%\end{array}$ & $\begin{array}{l}\text { A. fumiga- } \\
\text { tus } \%\end{array}$ & $\begin{array}{l}\text { F. oxyspo- } \\
\text { rum \% }\end{array}$ & $\begin{array}{l}\text { C. albicans } \\
\%\end{array}$ & $\begin{array}{l}\text { G. candi- } \\
\text { dum } \%\end{array}$ & $\begin{array}{l}\text { B. derma- } \\
\text { tidis } \%\end{array}$ & Total \% \\
\hline $\begin{array}{l}\text { Distal subungual } \\
\text { onychomycosis }\end{array}$ & $9(27.3)$ & $6(18.2)$ & $2(6.1)$ & $1(3.0)$ & - & - & - & - & - & $18(54.5)$ \\
\hline $\begin{array}{l}\text { White superficial } \\
\text { onychomycosis }\end{array}$ & - & - & - & $2(6.1)$ & $3(9.1)$ & $2(6.1)$ & - & $1(3.0)$ & $1(3.0)$ & $9(27.3)$ \\
\hline $\begin{array}{l}\text { Proximal subungual } \\
\text { onychomycosis }\end{array}$ & $1(3.0)$ & $1(3.0)$ & $2(6.1)$ & - & - & - & - & - & - & $4(12.1)$ \\
\hline $\begin{array}{l}\text { Candida } \\
\text { onychomycosis }\end{array}$ & - & - & - & - & - & - & $2(6.1)$ & - & - & $2(6.1)$ \\
\hline Total & $10(30.3)$ & $7(21.2)$ & $4(12.1)$ & $3(9.1)$ & $3(9.1)$ & $2(6.1)$ & $2(6.1)$ & $1(3.0)$ & $1(3.0)$ & $33(36.7)$ \\
\hline
\end{tabular}

out of 33 culture positive cases. A.niger and A.fumigatus was predominantly recorded from white superficial onychomycosis patients. Fusarium oxysporum, G.candidum and B.dermatitidis was isolated from 4 patients of white superficial onychomycosis patients (Table 3). Candida albicans was isolated from 2 (6.1\%) patients of Candida onychomycosis. Distal subungual onychomycosis was found most common clinical type of onychomycosis. Being the most common, this type of onychomycosis contributed the highest number of culture positive cases.White superficial onychomycosis was the second common most clinical type of onychomycosis and reported in 9 (27.3\%) patients out of 33 culture positive cases. Proximal subungual onychomycosis generally affects the toenails and fingernails equally. This clinical type was found uncommon and reported from 4 (12.1\%) patients, out of 33 culture positive cases. Candida onychomycosis was also found uncommon clinical type of onychomycosis and reported from $2(6.1 \%)$ patients. Out of 90 patients of onychomycosis, 60 (66.7\%) patients were infected with toenail. In nail infection, it was reported that, toe nails were more likely to be infected than the fingernails. Out of 18 culture positive cases of distal subungual onychomycosis, the maximum number of patients was found in the age-group of 41-50 followed by 51-60 and 31-40 years (Table 2 and Fig. 2). White superficial onychomycosis was reported in the age groups of 41-50, 51-60 and more than 60 years. All the four clinical types of onychomycosis was found more prevalent in the age group of 41-50 and 51-60 years. It was uncommon in the age groups of 0-15 and 16-30 years. Out of 33 culture positive cases of onychomycosis, 27 (81.8\%) were males and $6(18.2 \%$ ) were females (Table 2). In the present study, majority of the patients that are infected with onychomycosis were of service class and sports category. These two categories was found more susceptible to onychomycosis followed by labours, housewives, unemployed, students and farmers (Table 4 and Fig. 3).

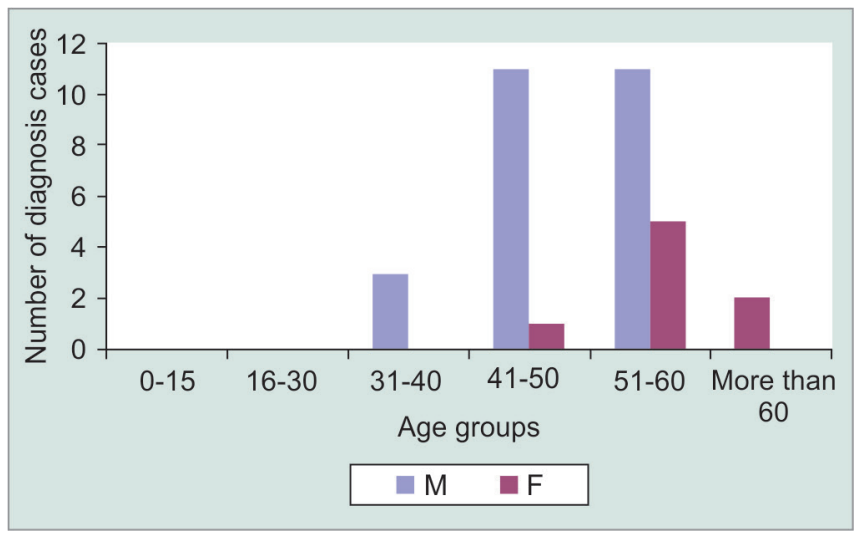

Fig. 2: Distribution of onychomycosis patients positive by culture according to sex and age groups

\section{Discussion}

Distal subungual clinical type of onychomycosis was found most common followed by white superficial onychomycosis in the present study. This finding corroborating with Kaur et al. ${ }^{5}$ and Malik et al who also reported distal subungual onychomycosis as most common clinical type. ${ }^{7}$ Malik et al also reported that dermatophytes are the most common pathogen of onychomycosis but the non dermatophyte molds and yeast were found as a causative agents in onychomycosis from Military Hospital, Rawalpinda ${ }^{7}$. Kaur et al. (2008) in their studies also reported three species of dermatophytes, i.e T.rubrum, T.mentagrophytes and T.tonsurans as etiological agent of Distal subungual onychomycosis ${ }^{5}$. Clinical diagnosis of onychomycosis revealed that dermatophytes are the most frequently implicated causative agent in onychomycosis ${ }^{5}$. 
Table 4: Distribution of onychomycosis patients according to profession

\begin{tabular}{lll}
\hline Age-group & Number of patients & \% of patients \\
\hline Students & 2 & 6.1 \\
Farmers & 1 & 3.0 \\
Housewives & 4 & 12.1 \\
Labours & 5 & 15.6 \\
Service class & 10 & 30.3 \\
Unemployed & 4 & 12.1 \\
Sportsmen & 7 & 21.2 \\
\hline
\end{tabular}

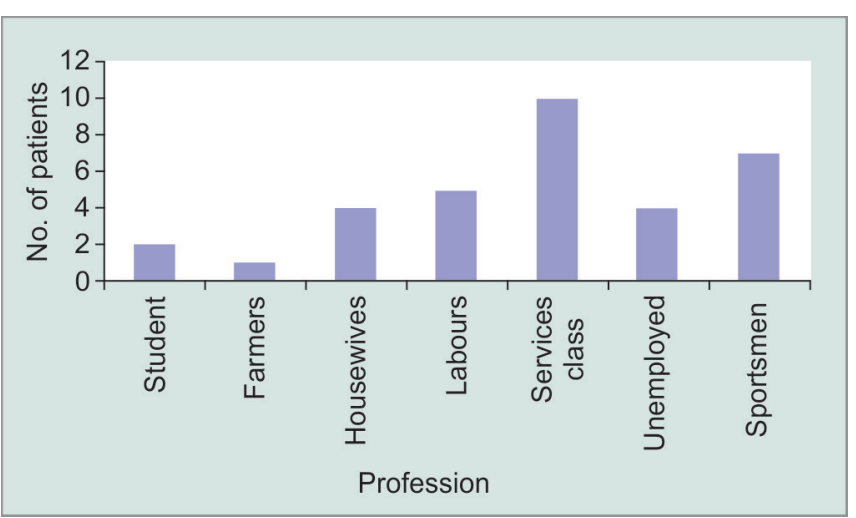

Fig. 3: Distribution of onychomycosis patients according to profession osis patients positive by culture according to sex and age groups

According to Williams (1993) the prevalence rate of onychomycosis was determined by age factor, social class, occupation, climate, living environment and frequency of travel ${ }^{8}$.In the study, prevalence of onychomycosis increases with age, due to poor peripheral circulation, diabetes, repeated nail trauma, longer exposure to pathogenic fungi, sub optimal immune system, wearing occlusive foot wears for exercise. In children onychomycosis was not reported due of faster nail growth, smaller nail surface for invasion and strong immune system. Elewski and Charif, Odom (1994) also found the highest prevalence of onychomycosis in higher age groups and also suggeste same reasons diabetes, weak immune system and wearing of shoes and socks., ${ }^{9,10}$

Present results are also in agreement with Malik et al who also reported 26 (65\%) males and 14 (35\%) females ${ }^{7}$. The increased prevalence of onychomycosis in men compared to women could be the result of more traumas in men compared to women and more common occlusive footwear and greater work activity. Our results are also coincides with Williams (1993) and Kaur et al who also reported toe nails are about 25 times more likely to be infected than finger nails ${ }^{5,8}$ Adhikari et al isolated the dermatophyte namely T.tonsurans as well as molds other than dermatophytes from onychomycosis patients in Gangtok, Sikkim ${ }^{11}$

\section{Conclusion}

Onychomycosis becomes a chronic disease and more difficult to treat due to added secondary bacterial infection. So, if the surveillance of this infections and the awareness level in the common population is increased, the burden of this type of disease can be reduced to much lower level. There is need for microbiological confirmation in case of onychomycosis for appropriate management of onychomycosis cases and further epidemiological study.

\section{References}

1. Scher RK: Onychomycosis: a significant medical disorder. J Am Acad Dermatol. 1996; 35; 2: 2-5.

2. Campbell C, Johnson EM: The dermatophytes. In: Collier L, Balows A, Sussman, editors. Topley and Wilson's Microbiology and Microbial infections, Vol 4. 9th ed. Arnold: London; 1998. p. 215-236.

3. Rippon JW, editor: The pathogenic fungi and pathogenic actinomycetes. Medical Mycology. 3rd ed. Saunders: Philadelphia; 1998; 169-275.

4. Scher RK, Baran R: Onychomycosis in clinical practice: factors contributing to recurrence. Br J Dermato1. 2003; 149: 5-9.

5. Kaur R, Kashyap B, Bhalla P. Onychomycisis-epidemiology, diagnosis and management. Indian J Medical Microbiology. 2008; 26: 10816.

6. Ellis DH, Marley JE, Watson AB, Williams TG. Significance of non dermatophyte moulds and yeasts in onychomycosis. Journal of Dermatology. 1997; 194(1):40-42.

7. Malik NA, Raza N, et al. Nondermatophytemoulds and yeasts as causative agents in onychomycosis.Journal of Pakistan Association of Dermatologists 2009;19:74-78.

8. Williams HC. The epidemiology of onychomycosis in Britain. $\mathrm{Br} J$ Dermatol. 1993;129:101.

9. Elewski BE, Charif MA. Prevalence of onychomycosis in patients attending a dermatology clinic in northeastern Ohio for other conditions. Archives of Dermatology. 1997; 133: 1172-1173.

10. Odom RB.Common superficial fungal infections in immunosuppressed patients.Journal of the American Academy of Dermatology.1994; 31: S56-S59.

11. Adhikari L, Das Gupta A, Pal R, Singh TSK. Clinico-etiologic correlates of onychomycosis in Sikkim. Ind J Pathol Microbiol. 2009:52(2):194197. 